NSRDS

ENCE DATA SY

NBS

PUBLICATIONS

National Standard

Reference Data System

Plan of Operation

U.S. DEPARTMENT OF COMMERCE

NATIONAL BUREAU OF STANDARDS

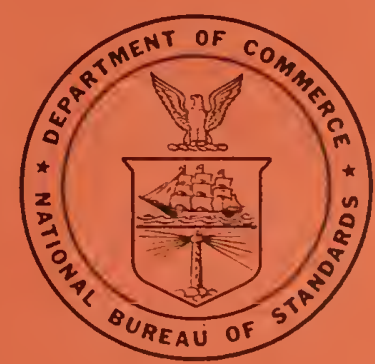




\section{THE NATIONAL BUREAU OF STANDARDS}

The National Bureau of Standards is a principal focal point in the Federal Government for assuring maximum application of the physical and engineering sciences to the advancement of technology in industry and commerce. Its responsibilities include development and maintenance of the national standards of measurement, and the provisions of means for making measurements consistent with those standards; determination of physical constants and properties of materials; development of methods for testing materials, mechanisms, and structures, and making such tests as may be necessary, particularly for government agencies; cooperation in the establishment of standard practices for incorporation in codes and specifications; advisory service to government agencies on scientific and technical problems; invention and development of devices to serve special needs of the Government: assistance to industry, business, and consumers in the development and acceptance of commercial standards and simplified trade practice recommendations; administration of programs in cooperation with United States business groups and standards organizations for the development of international standards of practice; and maintenance of a clearinghouse for the collection and dissemination of scientific. technical, and engineering information. The scope of the Bureau's activities is suggested in the following listing of its four Institutes and their organizational units.

Institute for Basic Standards. Electricity. Metrology. Heat. Radiation Physics. Mechanics. Applied Mathematics. Atomic Physics. Physical Chemistry. Laboratory Astrophysics.* Radio Standards Laboratory: Radio Standards Physics; Radio Standards Engineering.** Office of Standard Reference Data.

Institute for Materials Research. Analytical Chemistry. Polymers. Metallurgy. Inorganic Materials. Reactor Radiations. Cryogenics.** Office of Standard Reference Materials.

Central Radio Propagation Laboratory. * Ionosphere Research and Propagation. Troposphere and Space Telecommunications. Radio Systems. Upper Atmosphere and Space Physics.

Institute for Applied Technology. Textiles and Apparel Technology Center. Building Research. Industrial Equipment. Information Technology. Performance Test Development. Instrumentation. Transport Systems. Office of Technical Services. Office of Weights and Measures. Office of Engineering Standards. Office of Industrial Services.

* NBS Group, Joint Institute for Laboratory Astrophysics at the University of Colorado.

* Located at Boulder, Colorado. 


\title{
National Standard Reference Data System Plan of Operation
}

Edward L. Brady and Merrill B. Wallenstein

\author{
NSRDS-NBS 1 \\ National Standard Reference Data Series \\ National Bureau of Standards-1 \\ (Category 1-General) \\ Issued December 30, 1964
}

For sale by the Superintendent of Documents, U.S. Government Printing Office Washington, D.C., 20402 - Price 15 cents 
Library of Congress Catalog Card Number: 64-62987 


\section{Foreword}

The National Standard Reference Data System is a government-wide effort to give to the technical community of the United States optimum access to the quantitative data of physical science, critically evaluated and compiled for convenience. This program was established in 1963 by the President's Office of Science and Technology, acting upon the recommendation of the Federal Council for Science and Technology. The National Bureau of Standards has been assigned responsibility for administering the effort. The general objective of the System is to coordinate and integrate existing data evaluation and compilation activities into a systematic, comprehensive program, supplementing and expanding technical coverage when necessary, establishing and maintaining standards for the output of the participating groups, and providing mechanisms for the dissemination of the output as required.

The NSRDS is conducted as a decentralized operation of nation-wide scope with central coordination by NBS. It comprises a complex of data centers and other activities, carried on in government agencies, academic institutions, and nongovernmental laboratories. The independent operational status of existing critical data projects is maintained and encouraged. Data centers that are components of the NSRDS produce compilations of critically evaluated data, critical reviews of the state of quantitative knowledge in specialized areas, and computations of useful functions derived from standard reference data.

For operational purposes, NSRDS compilation activities are organized into seven categories as listed below. The data publications of the NSRDS, which may consist of monographs, looseleaf sheets, computer tapes, or any other useful product, will be classified as belonging to one or another of these categories. An additional "General" category of NSRDS publications will include reports on detailed classification schemes, lists of compilations considered to be Standard Reference Data, status reports, and similar material. Thus, NSRDS publications will appear in the following eight categories:

Category
1
2
3
4
5
6
7
8

Title

General

Nuclear Properties

Atomic and Molecular Properties

Solid State Properties

Thermodynamic and Transport Properties

Chemical Kinetics

Colloid and Surface Properties

Mechanical Properties of Materials

Within the National Bureau of Standards publication program a new series has been established, called the National Standard Reference Data Series. The present report, which is in Category 1 of the above list, is Number 1 of the new series and is designated NSRDS-NBS 1.

A. V. Astin, Director. 


\section{Contents}

PAGE

Foreword _.

I. Introduction

II. Scope of the NSRDS

III. Types of Activities Appropriate for NSRDS _-_._._.

IV. Program Management _._._._._._. 5

V. Organization Structure _-_-_-_-_-_-_-_-_-_- 9

VI. Budgetary Plans _._. 10

VII. Conclusion-A Word to the Technical Community _-_._-- 10

Appendix A. Policy Statement. Federal Council for Science and Technology Committee on Scientific Information, 28 May 1963.

Appendix B. Press Release. Office of Science and Technology, Executive Office of the President, June 1, 1963 


\title{
National Standard Reference Data System
}

\author{
Plan of Operation
}

\author{
Edward L. Brady and Merrill B. Wallenstein
}

\begin{abstract}
In June 1963 the National Bureau of Standards was assigned the responsibility by the President's Office of Science and Technology of administering a government-wide program to promote and coordinate systematic data compilation and evaluation activities in all fields of the physical sciences. This government-wide program has been called the National Standard Reference Data System. The present report describes the background of this program and the mode of approach adopted by the management of the National Bureau of Standards in fulfilling its responsibility.
\end{abstract}

\section{Introduction}

Much attention in the technical community of the United States has been focused recently on methods of improving techniques of processing and evaluating technical information in order to increase efficiency and speed progress in science and technology. The general problem of bettering the transfer of scientific and technical information from the originator to the user has been studied by a number of groups, including the President's Science Advisory Committee, the Federal Council on Science and Technology, the Senate Committee on Government Operations, the House of Representatives' Committee on Science and Astronautics, the National Science Foundation, the National Academy of Sciences-National Research Council, and committees of professional societies. Various new activities have been initiated as a result of the conclusions drawn in these studies and others are under consideration.

This report deals with one of the new governmental programs which has been established-the National Standard Reference Data System. It is an effort to cope with one aspect of the broad science information problem-namely, the production and dissemination of compilations of critically evaluated, quantitative data on the physical and chemical properties of materials. The value of such compilations is far-reaching and well recognized; data of known reliability are thereby made conveniently available for use by the scientist or engineer to design an experiment or a piece of hardware; the individual worker is relieved of the necessity of searching the literature and attempting to evaluate data in fields in which he is not expert; areas in which additional work is needed become more clearly defined; and relationships not previously apparent are recognized.

The nature of basic research in physical science and technology inherently involves in most cases making a quantitative measurement of some property of a material or system. The results of these measurements are very seldom an end in themselves. They contribute to an understanding of the structure and natural processes of the world in which we live; they form the basis for applied research; and they are needed for engineering and design activities. In principle, the publication of these data in journals and reports makes them available to those scientists and engineers who need them. In practice, however, there are two major difficulties: first, the great physical effort required to survey the literature to discover relevant data and, second, the intellectual effort of evaluating the worth of the data. 
In some fields of science and technology both of these operations must be carried out by the individual scientist or engineer himself. In other fields, organized groups perform one or both of these functions quite satisfactorily. Indeed, from the earliest days of recorded science there have been systematic compilation and evaluation programs in special areas, some undertaken because the compiler needed the data to further his own research, others because of a general need felt throughout a community of scientists or applied technologists. More than thirty years ago the National Academy of Sciences, recognizing the need for a comprehensive effort covering physical science and technology, sponsored the production of the International Critical Tables, a very useful work which is still widely consulted. No mechanism was established for the continuation of this program; the normal processes of scientific supply and demand were allowed to operate. These processes in the natural course of events led to the initiation of a large number of compilation and evaluation activities in various places throughout the world; an effort was made to stimulate additional activities through the establishment in 1955 of the Office of Critical Tables within the National Academy of Sciences-National Research Council. The OCT was directed to encourage the formation of new critical evaluation groups, to develop standards of criticality, to maintain a current knowledge of existing and continuing compilation efforts, and to participate in the development of international standards of units and nomenclature. In such activities the OCT's role was advisory; no directly sponsored operational program was envisioned.

During 1963, the Federal Council for Science and Technology reached the conclusion that the practices which had been customary in the past for compilation and evaluation efforts were no longer adequate for the needs of the technical community. This situation has been caused primarily by the rapid growth in the quantity of technical research and development and the accompanying growth of the literature during the past couple of decades. Statistics which indicate the rapid growth in quantity of data are impressive. For example, Chemical Abstracts published one million abstracts during its first thirty-two years of operation, a second million abstracts in seventeen years, and a third million in eight years. It is expected that the fourth million will require five years or less. (During 1963 Chemical Abstracts published approximately 170,000 abstracts.) Current estimates indicate that the total accumulated volume of scientific information of interest to chemists will double by the year 1975. Another interesting statistic is provided by the estimate of the National Science Foundation that the research projects which are described in research and development reports now cost an average of approximately $\$ 40,000$ each, at least when done in this country. Assuming, then, that each paper abstracted by Chemical Abstracts represents the equivalent of $\$ 40,000$, the total cost of the world research reported in 1963 by Chemical Abstracts corresponds to about 6.8 billion dollars.

The fraction of the world literature reported by Chemical Abstracts which is attributed to the United States is estimated to be $25.3 \%$ of the total, while the fractions attributed to the Soviet Union, the British Commonwealth, and Japan have been estimated to be $23 \%, 13 \%$, and $7.6 \%$, respectively. The increase in the number of papers has been reflected also in an increase in the number of journals in which technical literature is published. Various estimates, ranging up to 30,000 or more, have been made of the number of technical journals now being published throughout the world in which useful quantitative information in the physical sciences might be contained. Fortunately for the progress of science, the large majority of the useful information in any given field of specialty is normally published in only a relatively small number of journals, usually less than a hundred. Even this number, however, is more than the average specialist is prepared to keep up with. The result is not that important information remains forever buried but that 
the time lag for the incorporation of such information into the working body of useful knowledge of the specialist in the field is longer than is most efficient or desirable.

In addition to the physical effort of attempting to cover a large number of journals and papers, the individual scientist or engineer faces the problem of making a judgment on the value of the reported research. For example, often a decision must be made whether some newly reported measurement should supersede an older value, should be averaged in with older values to create a new value, or should be ignored entirely. These judgments can only be made by a specialist both in the field of the data and in the technique by which the data were obtained. In many, perhaps most, cases the user of the data will not be a specialist in the field but will be seeking a value to aid him in the interpretation of a related experiment in a different technical area, or perhaps to aid him in the design of a piece of apparatus, a chemical processing plant, or a new satellite. However, in other cases the user of a compilation may well be a specialist in that field and prefer to make his own evaluation; indeed, many scientists consider this exercise of judgement to be part of their responsibilities as scientists.

In some special fields of science the needs for compilations of evaluated data are being reasonably well satisfied. In other fields, uncritical compilations are being systematically prepared, leaving to the user the task of evaluation to fit his needs. In still other fields, neither of these kinds of activities exists, leaving the individual scientist or engineer without assistance in finding and evaluating the data he may need.

In order to ensure that scientists and engineers might have optimum access to evaluated data, the Federal Council for Science and Technology recommended to the Director of the President's Office of Science and Technology that a governmentwide, coordinated, comprehensive effort be established in the field of physical science. Accepting this recommendation, Dr. Jerome Wiesner promulgated a federal policy in June 1963, creating a National Standard Reference Data System and assigning to the National Bureau of Standards the responsibility for its administration. The general objective of this system is to coordinate and integrate existing data compilation and evaluation activities into a systematic program, supplementing and expanding technical coverage when necessary, establishing an maintaining standards for the output of the various groups, and providing mechanisms for the dissemination of the output as required. The full text of the federal policy statement is given as Appendix $A$ of this report and the press release announcing the establishment of the NSRDS* is given as Appendix B.

These official actions constituted an endorsement of a proposed plan of approach which had been developed over a period of several months by an ad hoc committee of staff members of the National Bureau of Standards appointed for the purpose by the Director of NBS. The general organization of the program at the National Bureau of Standards to be described later is very similar to that developed by the planning committee. This plan envisions a decentralized operation conducted across the country in many organizations by many individuals and groups, with central coordination managed by the National Bureau of Standards. Account is to be taken of all existing activities, and no attempt is to be made to take over direct operational management of existing groups, nor are new activities to be initiated in fields now adequately covered. The needs of the technical community are taken into consideration by calling upon groups of specialists for advice and for active assistance in planning and implementing the program. The program is envisioned as

\footnotetext{
*In this report the letters NSRDS are used to indicate the National Standard Reference Data System; that is, the complete complex of standard reference data activities which have been designated as part of the National Standard Reference Data System, whether at NBS or in other laboratories under NBS or other agency sponsorship. The letters NSRDP stand for the National Standard Reference Data Program at NBS: that is, the set of activities conducted directly by the administrative office for the NSRDS at NBS.
} 
permanent but with ever-changing internal emphasis in the many fields of knowledge as the requirements of the users of quantitative data change.

The assignment that was given to the National Bureau of Standards by the Office of Science and Technology includes the following tasks:

1. Operation of a National Standard Reference Data Center at the National Bureau of Standards.

2. Coordination of standard reference data activities of NBS, DOD, AEC, NASA, NSF, and other governmental agencies, all of which may operate components of the National Standard Reference Data System, if this is mutually decided to be appropriate.

3. Establishment of standards of quality for various products of the NSRDS.

4. Establishment of standards of methodology, including machine processing.

5. Establishment of standards for such other functions as are required to ensure the compatability of all units of the NSRDS.

This directive is very broad, indeed; obviously, some of the items listed above will require considerable thought, consultation, and technical progress before conclusions can be reached and action, if determined to be appropriate, can be taken. It is perhaps desirable at this point to reassure the readers of this report that the management of the National Bureau of Standards does not interpret this directive as a license to make arbitrary, unilateral decisions and attempt to impose them on groups outside its own operational jurisdiction. The manner in which the Director of the National Bureau of Standards proposes to fulfill the responsibilities assigned by the Office of Science and Technology will now be described in some detail.

\section{Scope of the NSRDS}

In order to develop a comprehensive plan of operation, it is necessary to decide which fields of science and technology should be included in the scope and, in those fields, which kinds of data are appropriate for collection and evaluation. These decisions have been made in general terms, recognizing that in many specific instances the question of appropriateness of inclusion of a particular kind of data will not be easy to answer. First, it has been decided that the program will be concerned only with physical phenomena. Phenomena in which biological effects are a significan factor will not be included. Second, it has been decided that the term "Standard Reference Data" would be defined as follows: Standard Reference Data means critically evaluated quantitative information relating to a property of a definable substance or system.

To obtain complete precision of meaning, most of the terms used in the above definition would themselves require definition. However, the purposes of the National Standard Reference Data Program do not require such precision. General, flexible guidelines on the scope of the program and appropriateness of specific activities are quite sufficient. Decisions will be made taking into consideration all relevant circumstances.

Operationally, these guidelines mean that the NSRDS shall not be concerned with the compilation of data relating to systems of uncertain, variable, or uncontrollable composition nor of data that are sensitive to unknowable details of the structure of the material. This principle carries with it the corollary that a system or material may be well-defined for one property but not for another. In putting this principle into practice, the program of the NSRDS must include careful examinations of the available data in a variety of fields in order to determine whether the data are appropriate for systematic compilation activities; that is, a critical review of the state of quantitative knowledge is first required. 
Application of the general guidelines also leads to the exclusion from the NSRDS of data whose value depends upon both the system or substance being measured and the measuring technique itself-in other words, data which are not characteristic of intrinsic properties of the system or substance. It is recognized that many such types of data have important applications and that the development of a comprehensive program for their compilation is worthy of serious consideration.

Additional types of data not considered appropriate for systematic activities in the System are those that relate to proprietary materials, those that have validity for only a limited time, and those that relate to materials which are of interest only for highly specialized commercial purposes.

\section{Types of Activities Appropriate for NSRDS}

The achievement of the objectives of the NSRDS require both the compilation of "standard reference data" and the "processing" of data-that is, gathering, sifting, and evaluating raw data and storing, retrieving, and disseminating evaluated data. For the compilation of standard reference data, four types of activities are considered to be appropriate in the program of the NSRDS:

1. Data collection and evaluation-scanning the literature to locate relevant data and background information, exercising critical judgment, and compiling the evaluated data in an orderly format.

2. Preparation of critical reviews-examination of the status of quantitative knowledge in a special aspect of a technical field, including a survey of experimental uncertainties and limitations and theoretical background, and development of new relationships between properties, as may be appropriate.

3. Computation of useful functions-computation of functions derived from standard reference data (e.g., thermodynamic functions), of values of theoretical or semi-empirical functions used in the interpretation of quantitative experiments, or of estimated values of unmeasured properties of important substances.

4. Experimental measurements-determination of experimental values of properties needed to fill gaps in tables, to extend the range of a parameter over which a property is measured, or to obtain a more precise figure. (It would not be considered appropriate to support research to develop a new or better measurement technique; experimental work would be undertaken only if a technique of known uncertainties would give useful information.)

In the data-processing type of activity it is planned to maintain both a design and research function and an operations function associated with the central office. The task of the research group is to identify and formulate the problems associated with the processing of the raw data and other information that constitute the working material of the data compilation groups and with the collection, storage, retrieval, and dissemination of the standard reference data. The research group also designs data handling systems as required to solve these problems, using manpower and facilities from the National Bureau of Standards or other groups, as appropriate. The task of the group given the operational responsibility is to provide the services to the technical community that are determined to be useful and to maintain the collection of data that will constitute the data center at the National $\mathrm{Bu}$ reau of Standards-indexing, filing, storing, and retrieving data as required.

\section{Program Management}

In order to plan the activities to be undertaken by the NSRDP, the field of physical science has been divided into a number of categories, each covering a field broad enough to include a large number of standard reference data compilation 
activities while at the same time retaining logical cohesiveness. In each field one person of high general competence can be expected to have a good working knowledge of the subject matter in the individual task areas in which standard reference data activities would be undertaken. For the initial phases of the program the following technical areas have been selected: (1) nuclear data, (2) atomic and molecular data, (3) solid state data, (4) thermodynamics and transport data, (5) chemical kinetics, (6) colloid and surface properties, and (7) mechanical properties of materials. Other categories will be added as the financial and manpower resources available to the Office of the NSRDS increase.

The planning and implementation of a program in each of these categories is the direct responsibility of a member of the staff of the Office of the NSRDS at the National Bureau of Standards. This responsibility involves the following steps, many of which are being taken concurrently over an extended period of time. Each category is to be further subdivided into areas of smaller scope, listing and organizing in a logical fashion the subfields which in the opinion of specialists comprise the broad category. In effect, this step constitutes a definition of the field. No two scientists seem to agree completely on the exact way in which this categorization should be carried out nor even on the names of the broad subdivisions. Certainly there is no uniquely ideal set of principles upon which to base such a classification. For practical purposes the ideal of unanimous agreement is not necessary; the goal is to obtain a system which can help to identify the activities which should be undertaken, to indicate the completeness of coverage of the various fields of science, and to judge the development of program activities from year to year.

Another step in the development of the program is a survey of the operations of existing data compilation and evaluation groups. This survey is to determine the technical scope covered, the nature of the output, the number and types of staff required, the financial arrangements, plans for the future, and any other relevant information.

Still another essential feature of the program is a determination of the needs of the technical community for activities of the type appropriate to the NSRDS. A great deal of information has been obtained during the survey of existing groups now under way. Additional information is obtained by consultation with individual specialists who use the data, with representatives of industrial and professional organizations (e.g. the Manufacturing Chemists' Association, The American Society for Testing and Materials, etc.), with committees of the National Academy of Sciences-National Research Council, with program officers in other government agencies, and with any other sources that seem appropriate.

As a result of the surveys and consultations a list of desirable activities can be prepared, with a priority assigned to each. No attempt will be made to develop a detailed scale of priorities; perhaps three levels at most will be quite sufficient. The area program leaders at the National Bureau of Standards have the responsibility for allocating the available funds to the various individuals and groups who are prepared to undertake activities, making the financial arrangements required, and monitoring the technical output of the various groups. Some of these groups are members of the technical divisions of the National Bureau of Standards, but the majority of the standard reference data compilation activities will be conducted outside the National Bureau of Standards-in academic institutions, in other government laboratories, and in industrial laboratories. No attempt will be made to stimulate new activities at the National Bureau of Standards unless the subject matter is one in which special competence already exists. In all cases direct operational supervision is the responsibility of the NBS division management or, if outside the NBS, that of the local technical supervision. The responsibility of the National Bureau of Standards' Office of Standard Reference Data is to ensure that 
quality standards are met and that the individual activities are well coordinated with each other. The authority of the NBS extends to control of the funds directly available to the NSRDP and to control of the designation of data compilation activities and products as components of the National Standard Reference Data System. Advice and recommendations will, of course, be provided to the sponsors of data activities supported by other governmental and non-governmental agencies, upon request.

The funds available initially are not sufficient to undertake every task identified as desirable nor is it possible in all cases to locate individuals both competent and willing to undertake some of the highest priority items. The mixture of activities which is selected and the allocation of funds to each will be the result of the exercise of judgment on the part of the program leaders, taking into account all technical, financial, and personnel considerations which seem relevant.

Although a single individual might be expected to have a good general knowledge in the broad scientific categories selected for the initial stages of operation, no one person can be expected to have the detailed knowledge necessary to accomplish all of the tasks required in the program planning stages just outlined. Hence, the program leader in each area works closely with a panel of consultants, each of whom is a specialist in an appropriate field. The participation of outstanding leaders of the technical community of the United States is being sought for these panels. They will be asked to make significant contributions during all of the planning and implementation of the program-to the definition of the area, to the appraisal of existing activities, to the assessment of priorities, to the recruitment of individuals and groups for specific data compilation and evaluation activities, to the evaluation of the technical output of the various groups under the cognizance of the NSRDS, and to any other tasks to which they are prepared to contribute. The recommendations of these panels will be perhaps the most important factor in the operational decisions made in the NSRDS.

In addition to seeking the aid of the panels of consultants just described, it is planned to confer at intervals with advisory committees established under the auspices of the National Academy of Sciences-National Research Council. Arrangements have been made with the Office of Critical Tables of the NAS-NRC to provide both the channel of communication with these advisory committees and also advice on the over-all operation of the NSRDS. In their fields of specialization, the NASNRC committees will be requested to discuss the general and specific problems encountered in the NSRDS, to review and criticize the NSRDS program, and in general to serve as a means of keeping the activities of the NSRDS in tune with the needs of the technical community.

An essential feature of the program is integration of existing governmentsponsored activities together with new programs into a coherent whole. This will require the establishment of an effective coordination mechanism, consisting partly of the formation of committees of appropriate representatives of the agencies concerned and partly of extensive liaison activities on the part of the members of the staff of the Office of the NSRDP.

Although the systematic planning operation described above is only in its early stages in each of the technical categories, it has been found desirable to begin a number of new and expanded standard reference data activities immediately, some within the National Bureau of Standards and some in outside organizations. These activities have all been considered by ad hoc panels assembled for the purpose and have been judged to be of high priority and interest.

Many, if not most, of the activities of existing data compilation and evaluation centers will be judged to be appropriate to the program of the National Standard Reference Data System. In accordance with the federal policy establishing the 
NSRDS (Appendix 1), such data centers which are sponsored and financed by any government agency may be designated as components of the NSRDS and called National Standard Reference Data Centers. The Office of the NSRDP will secure the agreement and cooperation of the agency concerned before entering into any arrangement with a center regarding its operation, designation as component of NSRDS, or financial support. Data centers not sponsored by any government agency are also eligible to become part of the NSRDS; the Office of NSRDS has authority to make mutually agreeable and desirable arrangements with such centers. It should be noted that the Office of the National Standard Reference Data Program plans to have no operational responsibility or authority over these data centers; its function will be advisory only. Opinions and recommendations regarding the operations of both government-supported and nongovernment-supported data centers and their designation as components of the National Standard Reference Data System will be submitted in the form of reports to the sponsoring agency, upon request. By mutual agreement with the sponsoring organization, the administrative office of the NSRDS may assume a portion of the responsibility for the financial support or for the technical monitoring of the operations of the data center.

The procedures by which it is planned to make the standard reference data produced under the cognizance of the NSRDS conveniently available to the technical public of the United States will now be discussed. As already pointed out, these data will be produced by a large number of individuals and groups associated with laboratories in all areas of the United States and probably in several other countries as well. Many of the institutions involved will have existing publication and distribution systems which are quite adequate and which the technical community has already learned how to use. Such existing systems will be encouraged to continue their operations and to expand to new fields and activities, if such expansion is determined to be appropriate. Hopefully, all products which satisfy the criteria of the NSRDS will ultimately be designated as such on all publications, regardless of the extent of financial support contributed by the administrative office of the NSRDS at the National Bureau of Standards.

The word "product" has been used in the preceding paragraph because of its broad, all-inclusive connotations. This word is intended to imply that many physical forms are considered appropriate for recording the results of compilation and evaluation activities. The product may be a separate monograph with a hard cover or a paper cover; it may be a critical review published in a recognized journal; it may be a set of IBM or other data-processing cards; it may be a computer tape or a computer print-out. In short, the product may take any form that the users of the data find to be most convenient.

In the planning of the detailed program, considerable study is being given to the nature of the services to be provided by the "Information Services Operation" of the Office of Standard Reference Data at the National Bureau of Standards. The guiding principles for the introduction of a service are that it shall be of value to the technical community and that it shall be concerned with compilations of evaluated data. The initial planning envisions the following activities. The data in storage will consist of a complete collection of the world output of "standard reference data," regardless of place of origin or physical form, appropriately indexed and stored for rapid retrieval. The file and compilations shall be accessible to all qualified persons who wish to use them, and information on their contents shall be made readily available to the technical community. An editorial and publication service shall be operated which will have the capability of turning the raw output from a data compilation group into a finished product, whether it be a monograph, a deck of IBM cards, a computer tape, or something else. An "Inquiry Service" shall 
be operated, which shall provide replies to specific questions that are asked; shall maintain a library of computer tapes and programs from which print-outs can be prepared to order; shall issue a "current awareness" periodical, probably quarterly, describing newly available compilations and the activities of data compilation groups throughout the world; and shall provide other services as they become desirable.

\section{Organization Structure}

Within the National Bureau of Standards, the Office of Standard Reference Data has been established as one of the functions of the Institute for Basic Standards, and the Chief of the Office reports to the Director of the Institute. The technical scope of the NSRDP is not encompassed completely by that of the Institute for Basic Standards, however, but extends into areas which are the responsibilities of other Institutes of NBS and also into areas in which none of the Institutes is presently active. An organizational diagram is shown as figure 1.

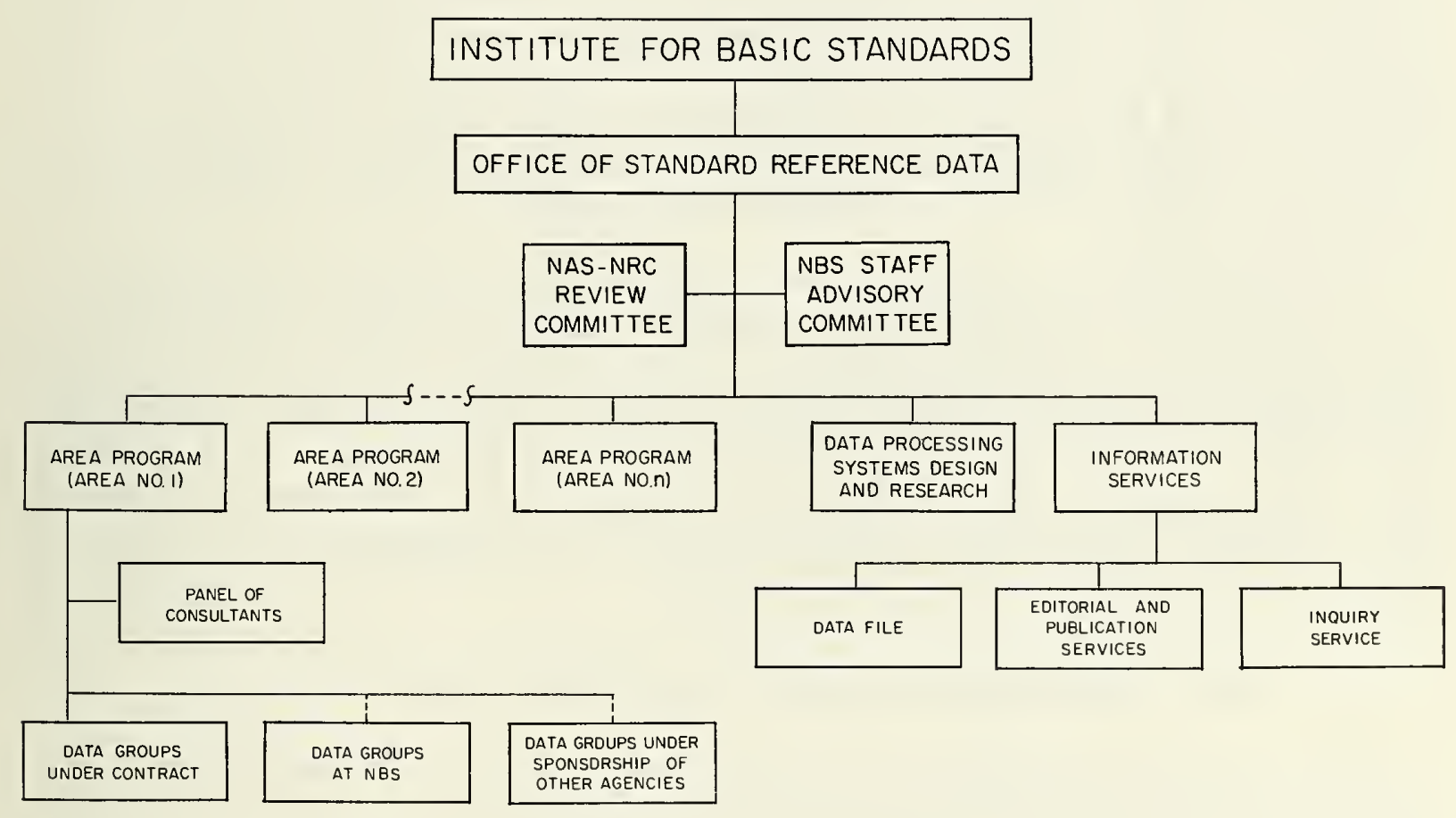

Figure 1. Organizational diagram 


\section{Budgetary Plans}

The funds made available to the NSRDP are to be used for new and supplementary activities of the standard reference data type. Financial responsibility for existing activities now under the sponsorship of other agencies will not be assumed by the NSRDP except in unusual circumstances, and certainly not until the most urgent needs for new projects have been satisfied. It has already become apparent during the earliest stages of establishment of the NSRDS that this point must be reiterated often. The program at NBS is not intended to supplant existing activities and sources of financial support but to augment them.

One mechanism that will be used to obtain increased financial support for needed projects is to enter into cooperative arrangements with industrial organizations and professional societies. By this means not only financial support but the guidance of industrial scientists familiar with the needs of their industries will be obtained.

In order to launch the NSRDP during Fiscal Year 1964, funds were transferred to NBS from the Atomic Energy Commission, the Department of Defense, the National Aeronautics and Space Administration, and the National Science Foundation. Responsible officials in these organizations have expressed great interest in the objectives of the NSRDS and the mechanics of the relationships between appropriate staff members of these agencies and of NBS are now being worked out. For FY 1965 and subsequent years it is planned to operate almost exclusively with funds included in the normal budget of the National Bureau of Standards. When a specific task is determined to be of unique interest to the mission of one government agency, recommendations will be made to that agency for its financial support.

Only very rough estimates can be made at the present time of the total financial and manpower resources being applied to standard reference data compilation and dissemination activities throughout the United States. A reasonable figure for the present expenditure of funds is probably $\$ 3 \mathrm{M}$ to $\$ 5 \mathrm{M}$ per year. Various estimates have been made of the desirable expansion, ranging up to a level four to five times as great as the present. The eventual level will, of course, depend largely on the usefulness of this kind of activity in promoting the efficiency and progress of science and technology in the United States.

\section{Conclusion-A Word to the Technical Community}

The persons responsible for the establishment of this program and for its management are convinced that the successful accomplishment of its aims will make an important contribution toward increasing the effectiveness of science and technology in the United States. To be successful will require not only the dedicated participation of hundreds of first-class technical men throughout the country to produce the critical evaluations and compilations required but also the participation of the whole community in using the products of the system and in letting its managers know how best to serve the users' needs. We seek the cooperation and assistance of the technical community in achieving our common goal of promoting the technical advancement of the United States. 


\section{Appendix A \\ FEDERAL COUNCIL FOR SCIENCE AND TECHNOLOGY COMMITTEE ON SCIENTIFIC INFORMATION 28 May 1963}

\section{Federal Policy on National Standard Reference Data System}

There will be established a National Standard Reference Data System (NSRDS) to provide on a national basis critically evaluated data in the physical sciences. The NSRDS will consist of a National Standard Reference Data Center (NSRDC) at the National Bureau of Standards and such other Standard Reference Data Centers as may be required.

The National Bureau of Standards will be charged with the administration of the National Standard Reference Data System. This assignment will include the establishment of standards of quality, methodology including machine processing formats, and such other functions as are required to ensure the compatibility of all units of the NSRDS.

The National Bureau of Standards will be charged with funding and administering the National Standard Reference Data Center. This Center will be an identifiable part of the National Scientific and Technical Information System (NSTIS).

Standard Reference Data Centers covering certain specific areas of effort may be established by or be assigned to the various Departments and Agencies in accordance with their specific desires and capabilities. Such Centers will be financed and administered by the Department to which assigned but will meet the quality standards and other requirements of the NSRDS. Such Centers will be included as identifiable components of the NSTIS.

The NSRDS may also include Standard Reference Data Centers at universities, research institutes, and other appropriate non-Government activities. To be included in the NSRDS, such Centers will meet the quality standards and other requirements of the NSRDS and will be included as identifiable components of the NSTIS.

There will be an Advisory Board to review and recommend policy relative to the operation of the NSRDS. It will include among others, representation from the National Academy of Sciences, National Science Foundation, Federal Agencies engaged in research and development, and such other representatives of the scientific and technical community as the Director of the National Bureau of Standards may determine.

In establishing the NSRDS, the intent is to provide an articulated system of Centers and activities under such coordination and direction as to ensure an output meeting quality standards for national reference data in the physical sciences. The establishment of the System should not be construed as preventing the establishment of such Federal or Departmental Data Systems as are required for the collection of raw or evaluated data to serve engineering or operating needs of the Federal Government or various Federal agencies. 


\section{Appendix B}

\section{OFFICE OF SCIENCE AND TECHNOLOGY EXECUTIVE OFFICE OF THE PRESIDENT June 7, 1963}

Dr. Jerome B. Wiesner, Director of the Office of Science and Technology in the Executive Office of the President, today announced the establishment of a National Standard Reference Data System. This national effort will be administered by the National Bureau of Standards, which is already compiling standard data. The System integrates to a single point of responsibility the present data-compiling activities of the National Bureau of Standards, Department of Defense, Atomic Energy Commission, Nationai Aeronautics and Space Administration, the National Science Foundation, and several other agencies.

The announcement follows the action taken by the Federal Council for Science and Technology, a government-wide group of top level agency officials in science and technology, based upon recommendations of its Committee on Scientific Information. According to Adm. Charles B. Martell of the Office of the Secretary of Defense, Chairman of the Committee on Scientific Information, the intent is to provide an articulated system of activities under such coordination and direction as to ensure a compilation of data meeting quality standards, and also to maintain continuous policy guidance of the system at the level of the Executive Office. The need to improve scientific and technical information in the Federal government has been increasingly apparent during recent years.

In making the announcement, Dr. Wiesner, who is also Chairman of the Federal Council for Science and Technology, stated that the Standard Reference Data System will greatly benefit United States engineers and scientists by giving them easy access to the data pertinent to their work. The standard source for scientific data has been the now almost totally out-dated International Critical Tables, an eight-volume publication last issued in 1933. That data source was compiled under the auspices of the National Academy of Sciences, Office of Critical Tables, and published by the McGraw-Hill Book Company.

Under the new system the National Academy of Sciences will act as advisor to the National Bureau of Standards, providing the guidelines to the fields of science and technology having greatest demand for data.

In recent years the mass of available data resulting from the stepped-up Federal research and development programs, has become much too large to be handled by a private publishing venture. Also, the flow of new data requires continuing efforts to update collections. Only a national system is able to cope with this information flow.

Under the plan for the new system, the data will be published in much smaller collections than in the old International Critical Tables. In this form, the data will be more responsive to the dynamics of modern research and development.

Detailed plans for the system components are presently being developed by the several participating agencies and the National Academy of Sciences. One set of these plans will be the subject of an all-day meeting on June 20, 1963, sponsored by the Office of Critical Tables, National Academy of Sciences. 

